\title{
Diminished Met Signaling in Podocytes Contributes to the Development of Podocytopenia in Transplant Glomerulopathy
}

\author{
Putri A. Agustian, ${ }^{\dagger \dagger}$ Mario Schiffer, ${ }^{\dagger \ddagger}$ \\ Wilfried Gwinner, ${ }^{\dagger \neq}$ Irini Schäfer, ${ }^{\ddagger}$ \\ Katharina Theophile, ${ }^{*}$ Friedrich Modde, ${ }^{*}$ \\ Clemens L. Bockmeyer, ${ }^{*}$ Jana Traeder, ${ }^{*}$ \\ Ulrich Lehmann, * Anika Großhennig, ${ }^{\S}$ \\ Hans H. Kreipe, ${ }^{*}$ Verena Bröcker, ${ }^{\star}{ }^{+}$ \\ and Jan U. Becker ${ }^{\star}$
}

\begin{abstract}
From the Institute of Pathology,* the Integrated Research and Treatment Center Transplantation, ${ }^{\dagger}$ the Department of Nephrology, ${ }^{\ddagger}$ and the Institute for Biometry, ${ }^{\S}$ Hannover Medical School, Hannover, Germany
\end{abstract}

Transplant glomerulopathy (TxG) can show secondary focal and segmental glomerulosclerosis (FSGS). FSGS in native kidneys is caused by podocytopenia. This study examines podocytopenia and the role of decreased paracrine Met activation on podocytes by decreased glomerular hepatocyte growth factor (HGF) levels in the development of podocytopenia in TxG. Podocytes were counted in 10 zero-hour biopsies and 10 specimens each with and without TxG. HGF/Met was examined with immunostains and quantitative RT-PCR in a set of three consecutive biopsies from 10 patients with TxG, including the diagnostic biopsy (DiagnBx) and the two previous biopsies (1stPrevBx and 2ndPrevBx). Antiapoptotic effects of HGF on podocytes were examined in vitro. Mean podocyte numbers per glomerulus were lower and glomerular volume higher in TxG. Fewer of the two preceding biopsies of the patients than of the controls contained phospho-Met(Tyr1349)-positive podocytes ( 2 of 8 versus 7 of 7 , $P=0.0070 ; 4$ of 9 versus 9 of $9, P=0.0294$ ). Glomerular HGF mRNA levels were lower in the 1stPrevBx of the patients $(0.049 \pm 0.083$ versus $0.284 \pm$ $0.331 ; P=0.0155)$. In vitro, HGF stimulation of podocytes resulted in antiapoptotic phosphorylation of AKT and extracellular signal-regulated kinase (ERK) and induction of X-linked inhibitor of apoptosis protein (XIAP). Decreased antiapoptotic Met signaling in podocytes, probably due to de- creased HGF secretion by glomerular epithelial cells, could contribute to podocyte loss and FSGS in TxG. (Am J Patbol 2011, 178:2007-2019; DOI: 10.1016/j.ajpath.2011.01.042)

Despite improvements in immunosuppressive therapy, which have successfully reduced the incidence of acute allograft rejection in transplant kidneys, chronic rejection remains a clinical challenge. ${ }^{1}$ Although interstitial fibrosis and tubular atrophy (IFTA) is multifactorial in origin, transplant vasculopathy and transplant glomerulopathy (TxG) are considered specific lesions of chronic allograft rejection. $^{2-7}$ The prevalence of TxG increases over time after transplantation from $5 \%$ at 1 year to $20 \%$ at 5 years. ${ }^{8}$ Early, subdiagnostic findings include an "activated" aspect of glomerular endothelial cells (GECs), with accumulation of mitochondria, Golgi apparati, and ribosomes, and a transition from fenestrated to continuous endothelium. ${ }^{9}$ Diagnostic findings are double contours of the glomerular basement membrane, visible by light microscopy, involving $10 \%$ or more of at least one glomerulus with mesangial proliferation. ${ }^{2}$ Similar changes are frequently present in the peritubular capillaries. ${ }^{10-12}$ This suggests a pathomechanism with primary endothelial damage throughout the kidney. This chronic endothelial damage is thought to be due to alloantibody fixation. ${ }^{8,12-14}$

Whereas the primary insult in TxG seems to be directed against GECs, other features of $T \times G$, such as proteinuria $^{8}$ and focal and segmental glomerulosclerosis $^{15}$ are typical indicators of podocyte damage. Proteinuria suggests podocyte damage, because podocytes are considered to be the most important component of the glomerular filter. ${ }^{16}$ FSGS suggests podocyte dam-

Supported by a grant from the German Federal Ministry of Education and Research (reference number: 01EO0802); the contents of this article are the sole responsibility of the authors.

Accepted for publication January 21, 2011.

Address reprint requests to Jan Ulrich Becker, M.D., Institute of Pathology, Hannover Medical School, Carl-Neuberg-Strasse 130625 Hannover, Germany. E-mail: janbecker@gmx.com. 
Table 1. Characterization of the Specimens That Served to Determine Podocyte Density in Renal Transplants With and Without TxG

\begin{tabular}{|c|c|c|c|}
\hline & \multicolumn{3}{|c|}{$n=10$} \\
\hline & Zero-hour Bx & Regular Bx without TxG & $T \times G$ \\
\hline Recipient sex (female:male) & $4: 6$ & $5: 5$ & $5: 5$ \\
\hline Donor type (living:cadaveric) & $3: 7$ & $6: 4$ & $0: 9$ (1 unknown) \\
\hline Donor sex (female:male) & $5: 5$ & $7: 3$ & 3:3 (4 unknown) \\
\hline Time after transplantation & $0 \pm 0.0$ months & $3 \pm 3.4$ months & $165 \pm 177.5$ months \\
\hline ai & $0.1 \pm 0.32$ & $0.4 \pm 0.52$ & $0.9 \pm 0.99$ \\
\hline at & $0.0 \pm 0.00$ & $0.3 \pm 0.67$ & $0.5 \pm 0.97$ \\
\hline$a v^{*}$ & $0.0 \pm 0.00$ & $0.0 \pm 0.00$ & $1.5 \pm 0.85$ \\
\hline $\mathrm{ag}^{*}$ & $0.0 \pm 0.00$ & $0.0 \pm 0.00$ & $1.2 \pm 1.03$ \\
\hline ptc & $0.0 \pm 0.00$ & $0.0 \pm 0.00$ & $0.8 \pm 1.23$ \\
\hline $\mathrm{Ct}^{*}$ & $0.1 \pm 0.32$ & $0.7 \pm 0.48$ & $3.0 \pm 0.00$ \\
\hline $\mathrm{Ci}^{*}$ & $0.1 \pm 0.32$ & $0.4 \pm 0.52$ & $3.0 \pm 0.00$ \\
\hline $\mathrm{CV}$ & $0.0 \pm 0.00$ & $0.0 \pm 0.00$ & $1.7 \pm 1.25$ \\
\hline $\mathrm{cg}^{*}$ & $0.0 \pm 0.00$ & $0.0 \pm 0.00$ & $2.8 \pm 0.42$ \\
\hline $\mathrm{mm}^{*}$ & $0.0 \pm 0.00$ & $0.0 \pm 0.00$ & $2.5 \pm 0.70$ \\
\hline ah & $0.6 \pm 0.70$ & $0.8 \pm 0.79$ & $1.8 \pm 1.23$ \\
\hline Banff C4d peritubular* & $0.0 \pm 0.00$ & $0.0 \pm 0.00$ & $1.3 \pm 1.49$ \\
\hline C4dglomerular & $0.0 \pm 0.00$ & $0.0 \pm 0.00$ & $0.9 \pm 1.10$ \\
\hline
\end{tabular}

Specimens included 10 each of the zero-hour biopsies (zero-hour Bx), transplant biopsies without TxG taken later after transplantation (regular Bx without TxG), and transplant nephrectomy specimens ( $T \times G)$ from 30 different patients.

Bx, biopsy; ai, acute extent of interstitial infiltrate at severity of acute tubulitis; av, severity of acute endothelialitis; ag, severity of acute glomerulitis; ptc, severity of peritubular capillaritis; ct, extent of tubular atrophy; ci, extent of interstitial fibrosis; cv, severity of chronic transplant vasculopathy; cg, severity of transplant glomerulopathy; mm, extent of mesangial expansion; ah, severity of arteriolar hyalinosis.

${ }^{*} P<0.05$.

age, because podocytopenia is considered necessary for its development. ${ }^{17,18}$ Podocytopenia has been observed in native kidneys in various glomerulopathies such as primary FSGS, ${ }^{19}$ IgA glomerulonephritis, ${ }^{20}$ hypertensive nephrosclerosis, ${ }^{21}$ diabetic glomerulosclerosis, ${ }^{22,23}$ Heymann nephritis, ${ }^{24}$ and recently, also in a rat model of chronic allograft nephropathy. ${ }^{25}$ These observations suggest that during the development of $T x G$, primary damage to the GECs causes secondary podocyte damage that ultimately leads to podocytopenia and FSGS, since podocytes are considered postmitotic cells that are unable to replicate. ${ }^{26,27}$ The mechanism of how primary damage to the GECs could cause secondary podocyte damage is currently unknown. A possible mechanism could be disruption of cytokine signaling from GECs to podocytes. Based on literature results, hepatocyte growth factor (HGF) could be a candidate. HGF was originally discovered as a potent mitogen for hepatocytes. ${ }^{28,29}$ The active form of HGF is a heterodimer $^{30}$ derived from a pre-proprecursor by proteolytic cleavage. ${ }^{31,32} \mathrm{HGF}$ is also known as a renotrophic factor, and the kidney is the organ with the highest HGF expression. ${ }^{33,34}$ Mesenchymal cells such as GECs, mesangial cells, fibroblasts, and macrophages secrete renal HGF, ${ }^{34,35}$ which has a promitogenic, ${ }^{33}$ antiapoptotic, ${ }^{36}$ cytoprotective, $^{37}$ and differentiation-preserving effect ${ }^{38}$ on a variety of renal cell types. HGF is the only known agonist of its receptor Met that becomes phosphorylated at tyrosine residues. ${ }^{39}$ Met is expressed in podocytes. $^{40,41}$ Met activation leads to phosphorylation of downstream mediators $\mathrm{AKT}^{42}$ and extracellular signalregulated kinase (ERK), ${ }^{43}$ which are both known to have antiapoptotic effects in general ${ }^{44}$ and also in podocytes. ${ }^{45,46}$ The present study tests the hypothesis that podocytopenia occurs in TXG and that disruption of the antiapoptotic HGF signal from GECs to podocytes is a possible cause of this podocytopenia. The association of $T \times G$ with podocytopenia is examined by glomerular morphometry in human zero-hour biopsies, regular transplant biopsies without TXG, and transplant nephrectomy specimens with TXG. The possible causative role of diminished HGF signaling is then examined retrospectively in human transplant biopsies with TxG and the two preceding biopsies, and in matched controls without $T \times G$ and in vitro in immortalized murine podocytes.

\section{Materials and Methods}

\section{Measurement of Podocyte Density in Zero-Hour Biopsies, Regular Transplant Biopsies, and Transplant Nephrectomy Specimens with TxG}

First, we tried to demonstrate podocytopenia in TxG. To this end, a set of each 10 zero-hour biopsies, 10 regular transplant biopsies without $\mathrm{T} \times \mathrm{G}$, and 10 transplant nephrectomy specimens with severe TxG (cg3 according to Banff criteria ${ }^{2}$ with secondary FSGS), each containing at least 30 glomeruli, were selected from the archives of the Institute of Pathology, Hannover Medical School. These specimens are characterized in Table 1 and derived from 30 different patients. Podocyte density could not be measured in the biopsy collective below in which the role of HGF signaling was examined, because most of these biopsies contained only between 10 and 20 glomeruli. The scarce tissue remaining in these blocks was mostly used for assessment of the HGF/Met signaling axis and did not suffice to estimate podocyte density. 


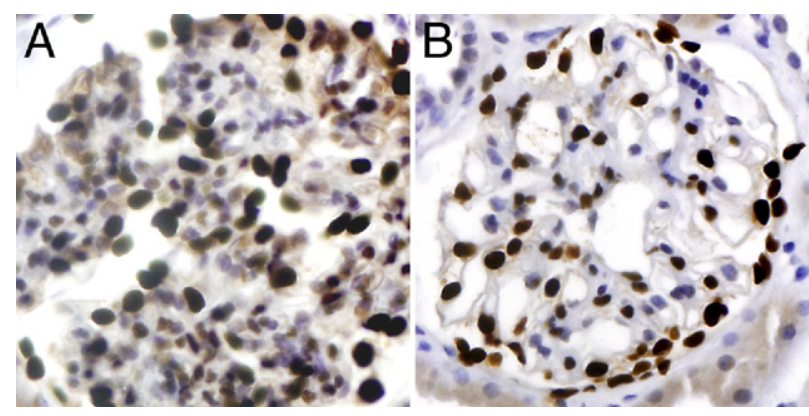

Figure 1. A: example of a glomerulus, podocyte nuclei with brown immunostaining for WT1 on a thick section $(8 \mu \mathrm{m})$. B: Glomerulus from the same specimen with the same immunostain on a thin section $(4 \mu \mathrm{m})$. Both, immunoperoxidase stain; original magnification, $\times 400$.

\section{WT1 IHC and Morphometry}

Mean glomerular volume, mean podocyte number per glomerulus, and mean podocyte volume density were calculated according to a method recently described, which counts Wilms' Tumor-1 (WT1)-positive podocytes by evaluation of thick and thin sections. ${ }^{47}$ Thick sections were cut at $8 \mu \mathrm{m}$, thin sections at $4 \mu \mathrm{m}$. Both thick and thin sections were stained in a Bond III automatic immunostainer according to the manufacturer's instructions using a mouse monoclonal primary antibody (WT1-562L-CE; Leica Microsystems, Wetzlar, Germany). Representative micrographs are displayed in Figure 1. JPEG images of 30 glomeruli were acquired from each specimen. The number of WT1-positive podocytes and also the glomerular area were determined with the public domain software ImageJ (http://rsbweb. nih.gov/ij/index.html, last accessed March 19, 2011). Podocyte nuclei in the glomerular tufts were identified by positive WT1 staining. Mean glomerular volume, mean podocyte number per glomerulus, and podocyte volume density were calculated as described previously. ${ }^{47}$ Calculations of the glomerular area and the different podocyte counts in the thick and the thin sections gave the podocyte volume density. Multiplication of the mean glomerular volume with the podocyte volume density yielded the mean podocyte number per glomerulus. ${ }^{47}$

\section{Examination of HGF/Met Signaling in Patient and Control Biopsies}

Next, we examined the possible role of decreased HGF/ Met signaling on podocytes in the development of podocytopenia in TxG. Patient biopsies (PBx) and control biopsies (CBx) were chosen from the archives of the renal transplant protocol biopsy program of the Hannover Medical School. Inclusion criterion for the PBx group was biopsy-proven transplant glomerulopathy (at least cg1 and $\mathrm{mm} 1$ according to the Banff components ${ }^{2}$ ) within 4 years after renal transplantation. Exclusion criteria were any other de novo or recurrent glomerular diseases. Ten TXG patients fulfilling these criteria were selected. As set out in Figure 2, from each of these $10 \mathrm{TxG}$ patients, the first biopsy that was diagnostic of TXG (DiagnBx) and the two preceding biopsies, the first and second pre- vious biopsies (1stPrevBx and 2ndPrevBx), were included in the study. For each of these biopsies, a matched control biopsy (DiagnBx, the 1stPrevBx, and the 2ndPrevBx), which was taken at the same interval after transplantation, was chosen from a cohort of patients in which the development of TxG within 4 years after transplantation was excluded by biopsy. Thus, 30 biopsies from 10 TxG patients (10 each DiagnBx, 1stPrevBx, and 2ndPrevBx) were compared with 30 biopsies from 22 control patients, that were matched for time after transplantation.

\section{Clinical Data}

Clinical data from the biopsies were retrieved from the registry of the renal transplant protocol biopsy program of the Hannover Medical School. Parameters included in the analysis were donor sex, donor age, donor serum creatinine level at explantation, cold ischemia time, number of human leukocyte antigen (HLA) mismatches, presence of panel reactive antibodies, recipient sex, recipient age, initial graft function, lowest serum creatine level within the first 6 weeks after transplantation, and immunosuppressive regimen.

\section{Routine Histological Evaluation According to Banff Criteria}

All biopsies were subjected to our routine histological work-up including multiple H\&E-, PAS-, and Jones-stained level sections and immunostains for C4d of formalin-fixed and paraffin-embedded tissue. In every biopsy that was

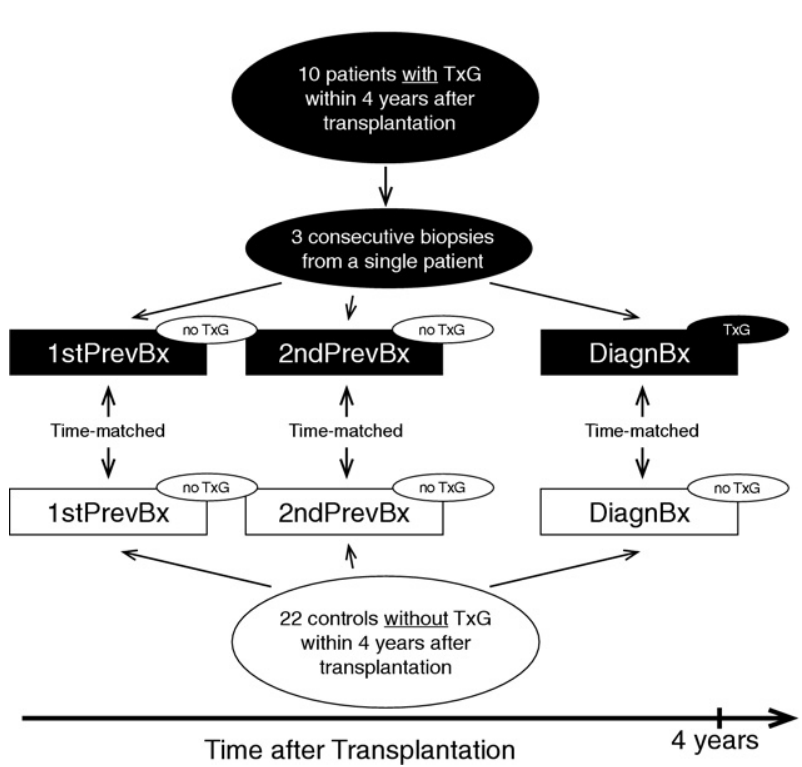

Figure 2. Selection of the patient biopsy (PBx) and the control biopsy $(\mathrm{CBx})$ : 10 patients with transplant glomerulopathy (TxG) within the first 4 years after transplantation were selected with their diagnostic biopsies (DiagnBx) and their two previous, nondiagnostic biopsies, the first and the second previous biopsy ( 1 stPrevBx and 2 ndPrevBx). For each of these 10 biopsy sets, time-matched control biopsies (CBx) were selected from a pool of 22 controls in which TxG within the first 4 years after transplantation was excluded by biopsy. Thus, 3 times 10 biopsies from patients were compared to 3 times 10 biopsies from controls. 
taken more than 1 year after transplantation, glomerulonephritis was excluded by IHC for IgA, IgG, IgM, C19, and $\mathrm{C} 3 \mathrm{c}$ and also by the ultrastructural examination described below. Results were reported according to the current definition of the Banff components. ${ }^{2,48-50}$ The currently unclassified C4d staining of GECs was graded as C4dglomerular0 to C4dglomerular3 with $0 \%,<10 \%$, $<50 \%$, and $>50 \%$ in analogy to Banff grading of peritubular capillary staining.

\section{Immunohistochemical Evaluation of HGF/Met-Signaling}

Formalin-fixed and paraffin-embedded kidney sections were deparaffinized in xylol and graded ethanols. Endogenous peroxidase and nonspecific avidin/biotin binding were blocked with $3 \% \mathrm{H}_{2} \mathrm{O}_{2}$ and Avidin/Biotin Blocking Kit (Vector Laboratories, Burlingame, CA). Sections were incubated overnight at $4^{\circ} \mathrm{C}$ with goat anti-human HGF IgG (AF-294-NA; R\&D Systems, Minneapolis, MN) at 1:10 dilution. Bound primary antibody was labeled with a biotinylated secondary rabbit anti-goat-antibody at 1:2000 (81-1640; Invitrogen, Carlsbad, CA) followed by incubation with streptavidin-horseradish peroxidase conjugate [ZytoChemPlus (HRP) Broad Spectrum Bulk Kit; Zytomed Systems, Berlin, Germany] for 30 minutes. Diaminobenzidine (DAB High Contrast Kit; Zytomed Systems) was used as the substrate. Immunohistochemical staining for phospho-Met(Tyr 1349) was performed similarly as previously described. ${ }^{51}$ Phosphorylation of tyrosine at position 1349 is essential to bind adapter proteins such as Gab1, which activate further pathways responsible for cell survival and proliferation. ${ }^{52,53}$ After antigen retrieval in citraconic acid anhydride at $98^{\circ} \mathrm{C}$ for 40 minutes, kidney sections were incubated overnight at $4^{\circ} \mathrm{C}$ with phosphoMet(Tyr1349) polyclonal rabbit antibody (\#3121; Cell Signaling Technology, Danvers, MA) at 1:50 dilution. A horseradish peroxidase detection system with $D A B$ as the substrate [ZytoChemPlus (HRP) Polymer Bulk Kit and DAB High Contrast Kit; both Zytomed Systems] was used to visualize the bound primary antibody. Slides from the manufacturer of the primary antibody (Cell Signaling Technology) were used as positive and negative control samples. HGF and phospho-Met(Tyr1349) immunostainings were scored as negative or positive. All sections were examined in a blinded fashion by two renal pathologists.

\section{Quantitative Real-Time PCR}

Formalin-fixed and paraffin-embedded renal biopsies were cut into $4-\mu \mathrm{m}$ sections. About 50 glomerular transections of each biopsy were microdissected on an mmi CellCut Plus System (Olympus, Hamburg, Germany) and collected for RNA isolation. Tissue was digested immediately in $50 \mu \mathrm{L}$ of Proteinase $\mathrm{K}$ solution at $20 \mathrm{mg} / \mathrm{mL}$ (Merck, Darmstadt, Germany), $50 \mu \mathrm{L}$ of RNA digestion solution (4.2 mol/L guanidinium thiocyanate, $30 \mathrm{mmol} / \mathrm{L}$ Tris- $\mathrm{HCl}$ of $\mathrm{pH} 7.6$, and $2 \%$ sodium N-lauroylsarcosine), and $0.5 \mu \mathrm{L}$ of 2 -mercaptoethanol at $55^{\circ} \mathrm{C}$ overnight. Then
$10 \mu \mathrm{L}$ of $3 \mathrm{~mol} / \mathrm{L}$ sodium acetate $(\mathrm{pH} 5.2), 63 \mu \mathrm{L}$ of Roti-Aqua-Phenol (Roth, Karlsruhe, Germany), and $27 \mu \mathrm{L}$ of chloroform were added to precipitate RNA. After phase separation through centrifugation, the aqueous phase (95 $\mu \mathrm{L}$ ) was carefully removed and added to $96 \mu \mathrm{L}$ of 2-propanol and $1 \mu \mathrm{L}$ of glycogen (20 mg/mL; Roche, Mannheim, Germany) as precipitation carrier. The precipitated RNA was then stored at $-20^{\circ} \mathrm{C}$.

CDNA synthesis was performed for 2 hours at $37^{\circ} \mathrm{C}$ as prescribed in the manual of the High Capacity CDNA Reverse Transcription Kit (Applied Biosystems, Foster City, CA). cDNA was preamplified using TaqMan PreAmp Master Mix (2X) (Applied Biosystems) according to the manufacturer's manual. The primer pool used for preamplification consisted of six TaqMan Assays (Applied Biosystems) including HGF, WT1, nephrin, and the three reference genes glyceraldehyde 3-phosphate dehydrogenase (GAPDH), $\beta$-glucuronidase (GUSB), and polymerase (RNA) II (DNA directed) polypeptide A (POLR2A). Twenty-five microliters of TaqMan PreAmp Master Mix as well as $12.5 \mu \mathrm{L}$ of the assay pool were added to $12.5 \mu \mathrm{L}$ of CDNA and subjected to the following thermocycler program: $95^{\circ} \mathrm{C}$ for 10 minutes, 14 cycles of $95^{\circ} \mathrm{C}$ for 15 seconds, and $60^{\circ} \mathrm{C}$ for 4 minutes. Preamplified cDNA was stored at $-20^{\circ} \mathrm{C}$.

Five microliters of the preamplified cDNA (1:10 dilution) were added to $15 \mu \mathrm{L}$ of master mix consisting of 10 $\mu \mathrm{L}$ of Gene Expression Master Mix (Applied Biosystems), $4 \mu \mathrm{L}$ of purified water, and $1 \mu \mathrm{L}$ of the respective TaqMan Gene Expression Assay (Applied Biosystems). Realtime PCR primers were used to amplify HGF (Hs 00900070_m1), WT1 (Hs 01103751_m1), nephrin (Hs 00190446_m1), POLR2A (Hs 00172187_m1), GAPDH (Hs 99999905_m1), and GUSB (Hs 99999908_m1). Real-time PCR was performed with a 7500 Fast RealTime PCR System (Applied Biosystems). Relative expression levels of target genes HGF, WT1 and nephrin

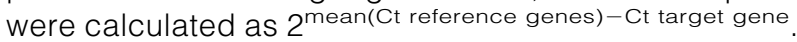

\section{Ultrastructural Examination}

Ultrastructural damage to GECs and podocytes was evaluated only in the PBx and the CBx. Minute samples of the renal cortex were embedded in Araldit CY212 (PLANO, Wetzlar, Germany) and analyzed with a transmission electron microscope (Zeiss EM10; Carl Zeiss, Oberkochen, Germany). Glomerular parameters in the ultrastructural examination were double contours of the lamina densa, widening of lamina rara interna, cytoplasmic swelling, and/or loss of fenestrae of GECs, and podocyte foot process effacement. Foot process effacement was estimated as a percentage in $10 \%$ increments; each of the other parameters was scored as 0 (absent), 1 (only one segment), 2 ( $\leq 50 \%$ of glomeruli), or $3(>50 \%$ of glomeruli). Peritubular capillaries were also evaluated regarding swelling of endothelial cells (absent or present) and multilamination of the peritubular basement membrane (one lamella: 0 , two to three lamellae: 1 , three to five lamellae: 2, >five lamellae: 3 ). 


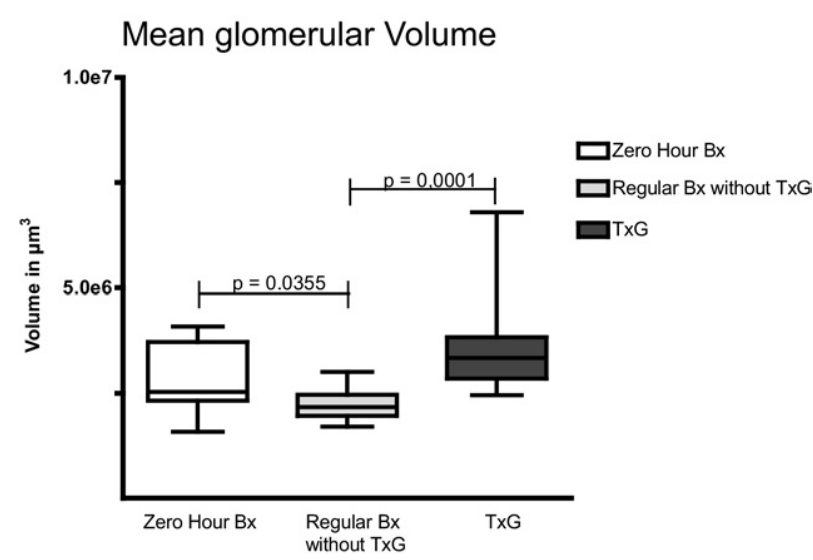

Figure 3. Mean glomerular volume in relation to specimen type: significantly lower mean volume was found in regular transplant biopsies without TxG. Also significantly larger mean glomerular volume was found in nephrectomy specimens with TxG than in specimens without. Depicted are the median, quartiles, minimum, and maximum. Bx, biopsy.

\section{TUNEL}

Glomerular apoptosis rates were examined with terminal deoxynucleotidyl transferase-mediated dUTP nick-end labeling (TUNEL) stains of formalin-fixed and paraffinembedded tissue sections with the ApopTag Peroxidase In Situ Detection Kit (S7101; Millipore, Billerica, MA) according to the manufacturer's instructions. Secondary follicles in formalin-fixed and paraffin-embedded human tonsil tissue served as positive controls.

\section{In Vitro Experiments using Podocyte Culture}

The HGF-driven activation of antiapoptotic signaling cascades by HGF in podocytes was examined in vitro. To this end, conditionally immortalized mouse podocytes (a gift from Peter Mundel, Mt. Sinai School of Medicine, New York, NY) were cultivated as described by Mundel and Kriz. ${ }^{54}$ To induce proliferation, cells were cultivated on type I collagen (BD Biosciences, Bedford, MA) at $33^{\circ} \mathrm{C}$ in the presence of $10 \mathrm{U} / \mathrm{mL}$ mouse recombinant $\gamma$-IFN (Cell Sciences, Canton, MA). A temperature change to $37^{\circ} \mathrm{C}$ and the absence of $\gamma$-IFN, maintained for 6 days, prompted the differentiation of the cells. Podocytes were stimulated with recombinant human HGF (Cell Sciences) at a concentration of $50 \mathrm{ng} / \mu \mathrm{L}$ on day 7 followed by harvesting as described below.

\section{Western Blots}

Cells were harvested for time-course analysis of proteins at the following time points: 0 minutes, 30 minutes, 60 minutes, 2 hours, 4 hours, 8 hours, and 24 hours. Podocytes were lysed on ice in radioimmunoprecipitation assay buffer [50 mmol/L Tris ( $\mathrm{pH} 7.5) ; 150 \mathrm{mmol} / \mathrm{L} \mathrm{NaCl}$; $0.5 \%$ sodium deoxycholate; $1 \%$ Nonidet P-40, and $0.1 \%$ SDS) containing protease inhibitor (Complete Mini; Roche), $100 \mathrm{mmol} / \mathrm{L}$ sodium orthovanadate, $1 \mathrm{~mol} / \mathrm{L} \mathrm{NaF}$, and $200 \mu \mathrm{g} / \mathrm{L}$ okadaic acid. Lysates were centrifuged at $4^{\circ} \mathrm{C}$ and $11,000 \mathrm{rpm}$ for 15 minutes to remove insoluble material. Protein concentration in the lysates was determined using the BCA Protein Assay Kit (Thermo Fisher Scientific, Rockford, IL). The samples were separated by $12 \%$ SDS-PAGE and transferred to polyvinylidene difluoride membranes (Immobilon-P; Millipore). The membranes were incubated overnight with anti-phospho-Met(Tyr1349) polyclonal rabbit antibody at 1:1000 dilution (\#3121, Cell Signaling Technology), anti-phospho-Akt (Ser473) monoclonal rabbit antibody at 1:2000 dilution (\#4060, Cell Signaling Technology), and anti-phosphop44/42 MAPK (ERK1/2) (Thr202/Tyr204) monoclonal rabbit antibody at 1:1000 dilution (\#4370, Cell Signaling Technology). We recently found that $X$-linked inhibitor of apoptosis (XIAP), which is known to inhibit caspase 3 , $7,{ }^{55}$ and $9,{ }^{56}$ is present in podocytes (unpublished data). Therefore, this antiapoptotic protein was examined with anti-XIAP monoclonal mouse antibody at 1:1000 dilution (\#610762, BD Biosciences, Franklin Lakes, NJ). HRPlabeled anti-mouse or anti-rabbit secondary antibodies (1:10,000), followed by enhanced chemiluminescence reagents (SuperSignalWest Pico STable Peroxide Solution and SuperSignalWest Pico Luminal/Enhancer Solution; Pierce Inc., Thermo Fisher Scientific) were used to visualize the antibody-antigen complexes.

\section{Statistical Analysis}

Statistics were calculated with JMP or StatView (SAS Institute, Cary, NC). For comparison of continuous variables, two-sided Kruskal-Wallis or Mann-Whitney $U$-tests were used; for nominal variables, two-sided $\chi^{2}$ or, when applicable, Fisher's exact tests were used. For dependent nominal variables, the two-sided McNemar test, implemented in StatXact 7.0 (Cytel, Cambridge, MA) was used. Since this is an exploratory study, the $P$ values were assessed descriptively.

\section{Ethical Approval}

All examinations were conducted according to the latest revision of the Declaration of Helsinki ${ }^{57}$ and were ap-

\section{Mean Podocytes per Glomerulus}

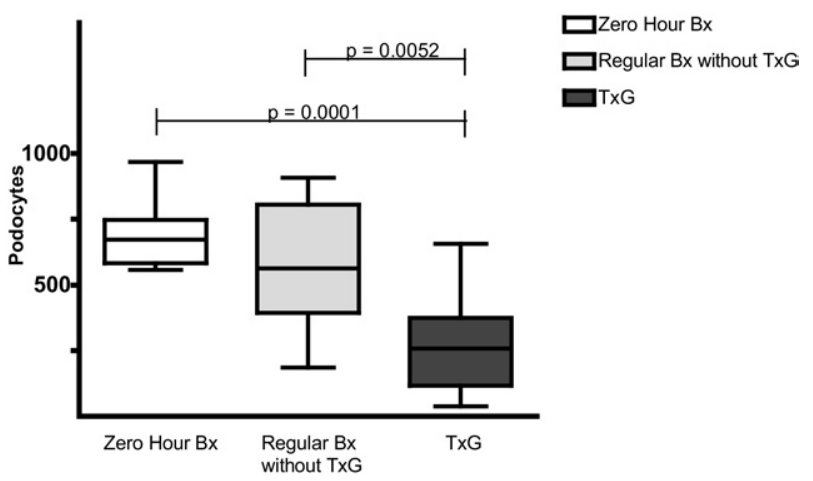

Figure 4. Mean podocyte number per glomerulus: significantly lower mean podocyte number per glomerulus was found in nephrectomy specimens with transplant glomerulopathy (TxG) than in zero-hour biopsies and regular transplant biopsies without TxG. Depicted are the median, quartiles, minimum, and maximum. 
Mean Podocyte Volume Density

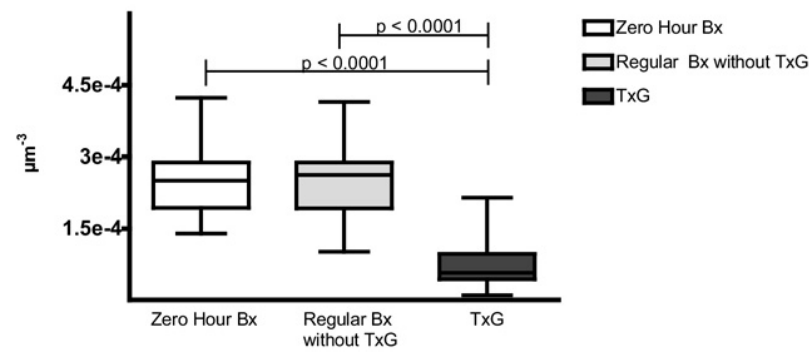

Figure 5. Podocyte volume density in relation to specimen type: significantly lower podocyte volume density was found in specimens with transplant glomerulopathy (TxG) than in zero-hour biopsies and regular transplant biopsies without TxG (regular Bx without TxG). Depicted are the median, quartiles, minimum, and maximum.

proved by the Ethics Committee of Hannover Medical School.

\section{Results}

\section{Mean Glomerular Volume, Mean Podocyte Number per Glomerulus, and Podocyte Volume Density}

The morphometric data regarding mean glomerular volume, podocyte volume density, and mean podocyte number per glomerulus are given in Figures 3 , 4, and 5. The mean glomerular volume was smaller in regular biopsies without TxG $\left(2.23 \pm 0.368 \times 10^{6} \mu \mathrm{m}^{3}\right)$ than in zero-hour biopsies $\left(2.88 \pm 0.814 \times 10^{6} \mu \mathrm{m}^{3} ; P=\right.$ $0.0355))$ and in nephrectomy specimens with TxG (3.60 \pm $1.222 \times 10^{6} \mu \mathrm{m}^{3} ; P=0.0001$ ). No difference regarding glomerular volume was found between zero-hour biopsies and nephrectomy specimens with TxG (Figure 3). Mean podocyte numbers per glomerulus were significantly lower in nephrectomy specimens with TxG $(265 \pm 181)$ than in zero-hour biopsies $(684 \pm 121 ; P=0.0001)$ and in regular biopsies without $\operatorname{TxG}(573 \pm 223 ; P=$ $0.0052)$. No significant difference was found between zero-hour biopsies and regular biopsies without $T x G$ (Figure 4).

Consequently, podocyte volume density was significantly lower in nephrectomy specimens with TxG $(0.8 \pm$ $0.56 \times 10^{-4}$ podocytes $/ \mu \mathrm{m}^{3}$ ) than in zero-hour biopsies $\left(2.5 \pm 0.76 \times 10^{-4}\right.$ podocytes $\left./ \mu \mathrm{m}^{3} ; P<0.0001\right)$ and in regular biopsies without TxG $\left(2.5 \pm 0.83 \times 10^{-4}\right.$ podocytes $\left./ \mu \mathrm{m}^{3} ; P<0.0001\right)$. No significant difference regarding podocyte volume density was found between zero-hour biopsies and regular biopsies without TxG (Figure 5).

\section{Clinical Data}

Clinical data of the 10 TxG patients and the 22 matched control patients are given in Table 2. Donor age and the number of HLA mismatches were significantly higher in the patients than in the controls. Although no significant difference regarding the donor serum creatinine could be found between patients and controls, the lowest serum creatinine level within the first 6 weeks after transplantation was higher in the patients than in the controls. No significant difference could be found in the other examined parameters between the patients and controls.

\section{Banff Components and Glomerular C4d}

A representative example of split glomerular basement membranes, reflected in the Banff cg component, and of mesangial matrix expansion reflected in the $\mathrm{mm}$ component, is given in Figure 6B. A synopsis of the Banff scores is shown in Table 3. Differences in the Banff components between PBx and CBx did not reach statistical significance, except for $\mathrm{cg}$ and $\mathrm{mm}$, which were defining criteria for the cohorts. C4d staining of glomerular or peritubular capillaries was not different between the groups (Table 3). When considering the presence of at least one of the three indicators of humoral rejection (transplant glomerulitis, peritubular capillaritis, or positive $\mathrm{C} 4 \mathrm{~d}$ staining in at least $10 \%$ of the peritubular capillaries) as indicators of acute humoral rejection, no significant differ-

Table 2. Clinical Parameters of the TxG Patients and the Control Patients

\begin{tabular}{lcc}
\hline & TxG patients $(n=10)$ & Control patients $(n=22)$ \\
\hline Donor sex (female/male) & $5: 5$ & $9: 13$ \\
Donor age & $65 \pm 10.7$ years & $53 \pm 13.5$ years* \\
Donor serum creatinine at explantation & $94.5 \pm 24.26 \mu \mathrm{mol} / \mathrm{L}$ & $97.7 \pm 41.01 \mu \mathrm{mol} / \mathrm{L}$ \\
Cold ischemia time & $11.7 \pm 7.73 \mathrm{hours}$ & $15.2 \pm 6.40 \mathrm{hours}$ \\
Number of HLA mismatches & $3.5 \pm 1.43^{*}$ & $2.0 \pm 1.68^{*}$ \\
Panel reactive antibodies present at time of transplantation & $0(0 \%)$ & $1(5 \%)$ \\
Recipient sex (female/male) & $4: 6$ & $15: 7$ \\
Recipient age & $54 \pm 11.4$ years & $50 \pm 13.0$ years \\
Initial graft function & $6(60 \%)$ & $13(59 \%)$ \\
Lowest serum creatinine within the first 6 weeks after & $190.2 \pm 63.41 \mu \mathrm{mol} / \mathrm{L}^{*}$ & $128.2 \pm 59.01 \mu \mathrm{mol} / \mathrm{L}^{*}$ \\
transplantation & $8(80 \%)$ & $17(77 \%)$ \\
Initial immunosuppression with cyclosporin A & $2(20 \%)$ & $4(18 \%)$ \\
Initial immunosuppression with tacrolimus & $1(10 \%)$ & $1(5 \%)$ \\
Initial immunosuppression with rapamycin & $7(70 \%)$ & $12(55 \%)$ \\
Initial immunosuppression with mycophenolate mofetil & $9(90 \%)$ & $21(95 \%)$ \\
Initial immunosuppression with corticosteroids & & \\
\hline
\end{tabular}

${ }^{*} P<0.05$ in Mann-Whitney U-test. 


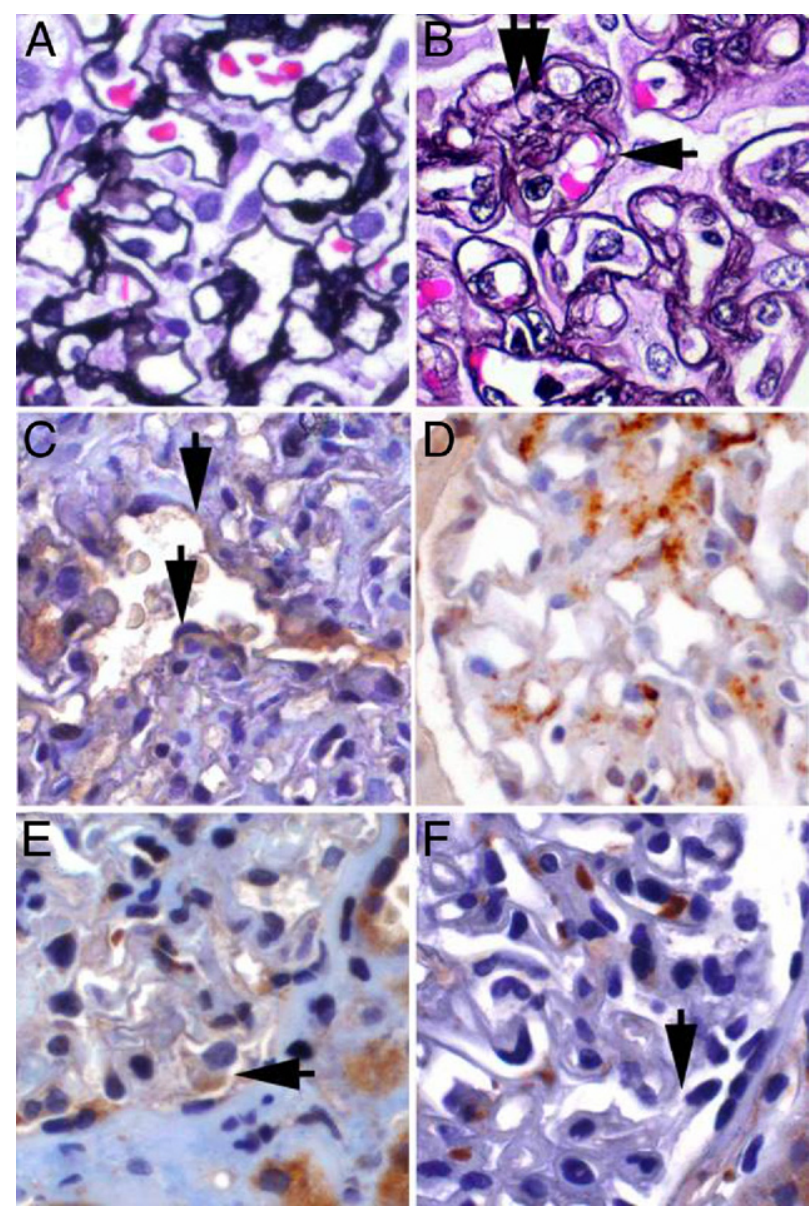

Figure 6. A: Normal glomerular morphology in one of the regular biopsies without TxG shows regular contours of the glomerular basement membrane and no mesangioproliferation. Jones stain; original magnification, $\times 600$. B: Typical histological findings of transplant glomerulopathy (TxG) with double contours of glomerular basement membrane (arrow) and mesangioproliferation (double arrow) in one of the transplant nephrectomy specimens with TxG. Jones stain; original magnification, $\times 600$. C: Glomerulus with HGF-positive (brown) glomerular endothelial cells (arrows) from one of the control cohort's (CBx) second previous biopsies (2ndPrevBx) D: Glomerulus with HGF-negative GECs and HGF-positive mesangial cells (brown) from one of the second previous biopsies (2ndPrevBx) of the patient cohort (PBx). Immunoperoxidase with hematoxylin counterstain; original magnification, $\times 600$. E: Phospho-Met (Tyr1349)-positive (brown) podocytes (arrow) in a second previous biopsy (2ndPrevBx) from the control cohort $(\mathrm{CBx})$. Immunoperoxidase with hematoxylin counterstain; original magnification, $\times 600$. F: Phospho-Met (Tyr1349)-negative podocyte (arrow) in a first previous biopsy (1stPrevBx) from the patient cohort. Two biopsies later, transplant glomerulopathy $(\mathrm{TxG})$ was histologically confirmed in this patient. Immunoperoxidase with hematoxylin counterstain; original magnification, $\times 600$.

ence could be found between $\mathrm{PBx}$ and $\mathrm{CBx}$ in the 1 stPrevBx ( 4 of 10 versus 2 of 10), the 2 ndPrevBx ( 6 of 10 versus 3 of 10), or the DBx (6 of 10 versus 2 of 10).

\section{Met and HGF IHC}

Representative examples of phospho-Met(Tyr1349) and HGF immunostains are given in Figure 6, C-F. Results of the phospho-Met(Tyr1349) immunostains of podocytes are given in Figure 7. Significantly less PBx than CBx had phospho-Met(Tyr1349)-positive podocytes in the 1stPrevBx (2 of 8 versus 7 of $7 ; P=0.0070$ ) and also in the 2ndPrevBx (4 of 9 versus 9 of $9 ; P=0.0294$ ). In the
DiagnBx, no significant difference could be found between CBx and PBx (4 of 7 versus 7 of 9).

There was no difference found in the phospho-Met(Tyr 1349) immunostains of mesangial cells between PBx and $\mathrm{CBx}$ at all time points examined (1stPrevBx, 0 of 8 versus 0 of $7 ; 2$ ndPrevBx, 4 of 9 versus 4 of 9 ; DiagnBx, 2 of 7 versus 2 of 9 ).

Similar to the mesangial cells, no significant differences were found in phospho-Met(Tyr1349) immunostaining of GECs between $\mathrm{PBx}$ and $\mathrm{CBx}$ at all time points examined (1stPrevBx, 3 of 8 versus 2 of $7 ; 2$ ndPrevBx, 3 of 9 versus 1 of 9 ; DiagnBx, 3 of 7 versus 2 of 9 ).

Also, no significant differences could be found in the ratio of biopsies with positive HGF immunostaining of GECs or mesangial cells between PBx and CBx in the 1stPrevBx (GECs, 5 of 9 versus 3 of 7 ; mesangial cells, 1 of 9 versus 0 of 7 ), the 2ndPrevBx (GECs, 1 of 9 versus 4 of 9; or mesangial cells, 5 of 9 versus 1 of 9 ), or the DiagnBx (GECs, 5 of 9 versus 7 of 10; or mesangial cells, 6 of 9 versus 3 of 10). However, in the PBx, a significant increase of biopsies with positive mesangial cells was apparent from the 1 stPrevBx (1 of 9 ) to the 2 ndPrevBx (5 of 9 ) and the DiagnBx (6 of 9 ).

\section{Quantitative Real-Time PCR}

Results of the quantitative real-time PCR analysis of HGF mRNA are given in Figure 8. Glomerular HGF mRNA was significantly lower in $\mathrm{PBx}$ than in $\mathrm{CBx}$ only in the 1stPrevBx (mean, $0.05 \pm 0.083$ versus $0.28 \pm 0.331 ; P=$ $0.0155)$, whereas in the 2 ndPrevBx $(0.06 \pm 0.095$ versus $0.04 \pm 0.053)$ and the DiagnBx $(0.16 \pm 0.190$ versus 0.03 \pm 0.063), differences between PBx and CBx did not reach statistical significance.

No significant difference in the levels of WT1 could be found between PBx and CBx (1stPrevBx, $4.09 \pm 2.396$ versus $3.87 \pm 4.078 ; 2$ dPrevBx, $8.66 \pm 10.538$ versus $9.70 \pm 5.801 ;$ DiagnBx, $3.83 \pm 2.724$ versus $6.41 \pm$ 3.348).

Also no significant difference could be found between the groups regarding expression levels of nephrin between $\mathrm{PBx}$ and $\mathrm{CBx}$ (1stPrevBx, $24.45 \pm 9.678$ versus $25.17 \pm$ 27.959; 2ndPrevBx, $36.01 \pm 45.848$ versus $50.52 \pm 34.654$; DiagnBx, $30.70 \pm 42.809$ versus $18.14 \pm 25.220$ ).

\section{TUNEL Stains}

In none of the specimens were TUNEL-positive cells found in the glomeruli (data not shown).

\section{Ultrastructural Examination}

No significant differences were found in the ultrastructural parameters double contours of the lamina densa, widening of the lamina rara interna, cytoplasmic swelling and/or loss of fenestrae of GECs, or extent of foot process effacement between $\mathrm{PBx}$ and $\mathrm{CBx}$. These parameters were as follows: Double contours of the lamina densa: 1stPrevBx score 0,7 of 8 versus 6 of 9 ; score 1,0 of 8 versus 3 of 9 ; score 2, 1 of 8 versus 0 of 9 ; score 3,0 of 8 versus 0 of 9 ; 2ndPrevBx score 0,5 of 7 versus 6 of 10; 
Table 3. Banff Components in the Patient Biopsies That Were Diagnostic for TxG and the Two Preceding Biopsies, 1stPrevBx and 2ndPrevBx

\begin{tabular}{|c|c|c|c|c|c|c|}
\hline & \multicolumn{6}{|c|}{$n=10$} \\
\hline & \multicolumn{2}{|c|}{ 1stPrevBx } & \multicolumn{2}{|c|}{ 2ndPrevBx } & \multicolumn{2}{|c|}{ DiagnBx } \\
\hline & PBx & $\mathrm{CBx}$ & $\mathrm{PBx}$ & $\mathrm{CBx}$ & PBx & $\mathrm{CBx}$ \\
\hline ai & $1.0 \pm 0.82$ & $0.8 \pm 0.79$ & $0.5 \pm 0.71$ & $0.4 \pm 0.52$ & $0.7 \pm 0.48$ & $1.0 \pm 0.94$ \\
\hline at & $0.5 \pm 0.97$ & $0.4 \pm 0.70$ & $0.3 \pm 0.48$ & $0.3 \pm 0.48$ & $0.1 \pm 0.32$ & $0.4 \pm 0.70$ \\
\hline av & $0.1 \pm 0.32$ & $0.1 \pm 0.32$ & $0.3 \pm 0.67$ & $0.1 \pm 0.32$ & $0.0 \pm 0.0$ & $0.0 \pm 0.0$ \\
\hline $\mathrm{ag}$ & $0.5 \pm 1.08$ & $0.0 \pm 0.0$ & $0.3 \pm 0.48$ & $0.3 \pm 0.67$ & $0.1 \pm 0.32$ & $0.0 \pm 0.0$ \\
\hline ptc & $0.3 \pm 0.67$ & $0.0 \pm 0.0$ & $0.1 \pm 0.32$ & $0.0 \pm 0.0$ & $0.6 \pm 0.84$ & $0.0 \pm 0.0$ \\
\hline $\mathrm{ct}$ & $0.7 \pm 0.67$ & $0.8 \pm 0.79$ & $0.4 \pm 0.52$ & $0.7 \pm 0.48$ & $1.3 \pm 0.82$ & $0.9 \pm 0.32$ \\
\hline $\mathrm{ci}$ & $0.6 \pm 0.70$ & $0.9 \pm 0.99$ & $0.3 \pm 0.48$ & $0.5 \pm 0.53$ & $1.1 \pm 0.99$ & $0.6 \pm 0.52$ \\
\hline $\mathrm{CV}$ & $0.2 \pm 0.63$ & $0.2 \pm 0.63$ & $0.1 \pm 0.32$ & $0.0 \pm 0.0$ & $0.2 \pm 0.42$ & $0.0 \pm 0.0$ \\
\hline $\mathrm{cg} *$ & $0.0 \pm 0.0$ & $0.0 \pm 0.0$ & $0.0 \pm 0.0$ & $0.0 \pm 0.0$ & $1.9 \pm 0.99$ & $0.0 \pm 0.0$ \\
\hline $\mathrm{mm} *$ & $0.0 \pm 0.0$ & $0.3 \pm 0.67$ & $0.3 \pm 0.48$ & $0.3 \pm 0.48$ & $1.3 \pm 0.67$ & $0.7 \pm 0.95$ \\
\hline ah & $0.1 \pm 0.32$ & $0.6 \pm 0.97$ & $0.7 \pm 0.82$ & $0.4 \pm 0.70$ & $0.7 \pm 0.95$ & $0.4 \pm 0.70$ \\
\hline C4d peritubular & $0.4 \pm 0.97$ & $0.4 \pm 0.84$ & $0.6 \pm 1.07$ & $0.4 \pm 0.84$ & $0.6 \pm 0.97$ & $0.4 \pm 0.84$ \\
\hline C4dglomerular & $0.8 \pm 1.03$ & $0.0 \pm 0.0$ & $0.9 \pm 1.29$ & $0.3 \pm 0.95$ & $0.7 \pm 1.16$ & $0.2 \pm 0.63$ \\
\hline
\end{tabular}

Data shown include C4d staining of peritubular capillary endothelial cells and GECs. Glomerular endothelial C4d staining (C4dglomerular) is not among the presently described Banff components; it is defined in analogy to the C4d scoring in the peritubular capillaries. Components are shown in comparison to control biopsies $(\mathrm{CBx})$ that were matched for time after transplantation. None of the components except for inclusion criteria cg and mm were different between the groups.

CBx, control biopsy: PBx, patient biopsy; ai, acute extent of interstitial infiltrate at severity of acute tubulitis; av, severity of acute endothelialitis; ag severity of acute glomerulitis; ptc, severity of peritubular capillaritis; ct, extent of tubular atrophy; ci, extent of interstitial fibrosis; cv, severity of chronic transplant vasculopathy; $\mathrm{cg}$, severity of transplant glomerulopathy; mm, extent of mesangial expansion; ah, severity of arteriolar hyalinosis.

score 1,0 of 7 versus 4 of 10 ; score 2,1 of 7 versus 0 of 10; score 3, 1 of 7 versus 0 of 10; DiagnBx score 0.4 of 7 versus 7 of 8 ; score 1,1 of 7 versus 0 of 8 ; score 2,0 of 7 versus 0 of 8 ; score 3,2 of 7 versus 1 of 8 . Widening of lamina rara interna: 1stPrevBx score 0,4 of 8 versus 4 of 9 ; score 1,3 of 8 versus 4 of 9 ; score 2, 1 of 8 versus 1 of 9 ; score 3 , 0 of 8 versus 0 of 9 ; 2ndPrevBx score 0 , 2 of 7 versus 4 of 10; score 1,2 of 7 versus 4 of 10 ; score 2, 2 of 7 versus 1 of 10; score 3, 1 of 7 versus 1 of 10 ; DiagnBx score 0,1 of 7 versus 4 of 8 ; score 1,4 of 7 versus 3 of 8 ; score 2, 2 of 7 versus 0 of 8 ; score 3,0 of 7 versus 1 of 8 . Cytoplasmic swelling and/or loss of fenestrae of GECs: 1stPrevBx score 0,1 of 8 versus 1 of 9; score 1, 2 of 8 versus 7 of 9; score 2, 2 of 8 versus 1 of 9 ; score 3,3 of 8 versus 0 of 9 ; 2ndPrevBx score 0,0 of 7 versus 1 of 10 ; score 1,2 of 7 versus 5 of 10; score

\section{Phospho-Met(Tyr1349) Immunostains of Podocytes}

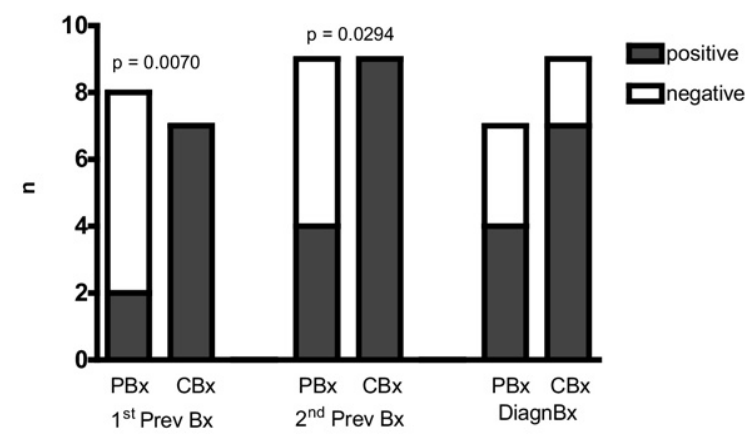

Figure 7. Frequency of biopsies with phospho-Me t(Tyr1349)-positive podocytes is lower compared to time-matched controls in the first (1stPre$\mathrm{vBx}$ ) and the second previous biopsies (2ndPrevBx) but not in the third consecutive biopsy in which transplant glomerulopathy (TxG) was diagnosed (DiagnBx). Results from immunoperoxidase stains.
2, 4 of 7 versus 4 of 10; score 3, 1 of 7 versus 0 of 10; DiagnBx score 0 , 0 of 7 versus 2 of 8 ; score 1,4 of 7 versus 5 of 8 ; score 2, 1 of 7 versus 1 of 8 ; score 3,2 of 7 versus 0 of 8 . Podocyte foot process effacement: 1 stPrevBx, $13 \% \pm 13.1 \%$ versus $5 \% \pm 3.5 \%$; 2 ndPrevBx, $25 \% \pm 34.2 \%$ versus $16 \% \pm 17.6 \%$; DiagnBx mean $10 \% \pm 4.1 \%$ versus $9 \% \pm 10.9 \%$.

\section{In Vitro Experiments}

Western blots showed sustained phosphorylation of Met on stimulation with human recombinant HGF at sites Tyr1234/5, lasting for 8 hours, and Tyr1349, lasting for about 8 hours. Activating phosphorylation of downstream

\section{Quantitative PCR HGF}

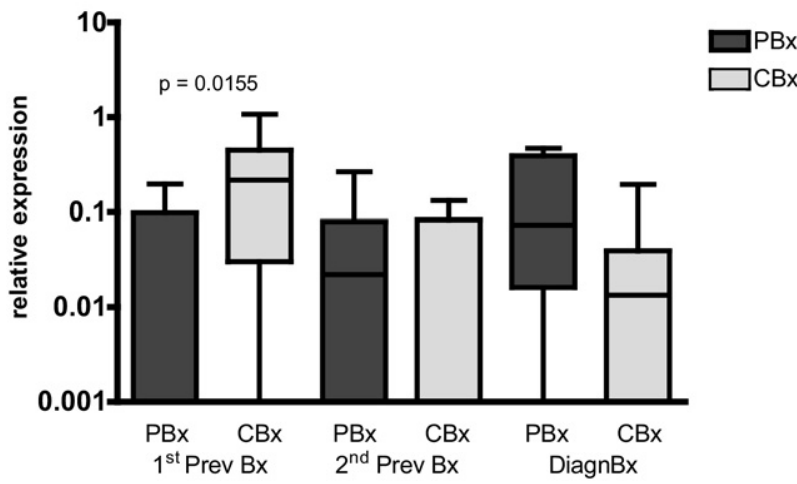

Figure 8. Relative levels of HGF-mRNA are significantly lower compared to controls in the first (1stPrevBx) of three consecutive biopsies from patients in which the third was diagnostic of transplant glomerulopathy (TxG). Results from quantitative real-time PCR experiments, relative to levels of the mean of three reference genes. Depicted are the median, quartiles, minimum, and maximum. 


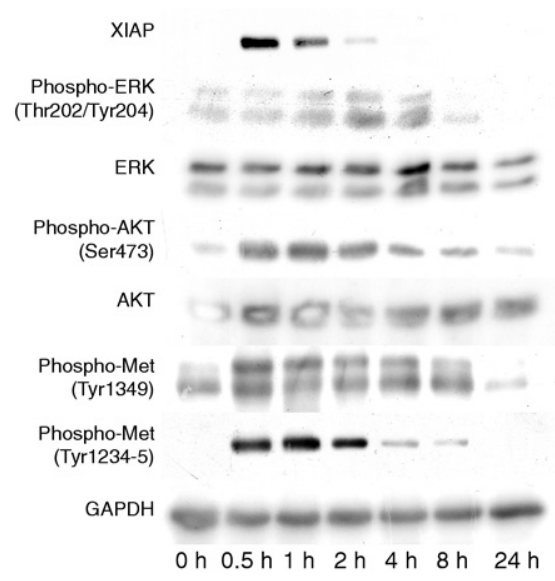

Figure 9. Western blot of cultivated mouse podocytes on stimulation with HGF: increased phosphorylation of Met at sites Tyr1234-5 and Tyr1349 beginning 0.5 hours after stimulation and lasting for about 8 hours. Further downstream in the signaling cascade, activating phosphorylation of antiapoptotic ERK at sites Thr202/Tyr204 and AKT at Ser473 occurs. Induction of XIAP, lasting for 2 hours, also can be observed.

antiapoptotic mediators AKT and ERK could be detected for about 4 to 8 hours. The antiapoptotic XIAP was induced after 30 minutes, lasting for 2 hours (Figure 9).

\section{Discussion}

The present study is the first, to our knowledge, to demonstrate podocytopenia in human TxG. A recent study in rats has shown the same in a model of chronic allograft nephropathy ${ }^{25}$ Both studies expand the paradigm that podocytopenia is a prerequisite of glomerular scarring, ${ }^{17,58,59}$ derived from studies of glomerulopathies in native kidneys to chronic rejection in transplant kidneys. Podocytopenia can be absolute, with decreased podocyte numbers per glomerulus, or relative, with stable numbers of podocytes in hypertrophic glomeruli. Mixed forms with decreased podocyte numbers in hypertrophic glomeruli probably also exist. Our findings support the hypothesis that podocytes are lost during the development of TxG and that absolute podocytopenia contributes to the development of secondary FSGS in TxG. Interestingly, glomerular volume was lower in the regular biopsies without TxG compared to both zero-hour biopsies and specimens with TxG. This is surprising, since glomerular hypertrophy could be expected to develop in a single kidney transplant. Studies in the 1990s have shown that, in nondiabetic recipients, glomerular volume does not increase but rather decreases after transplantation. ${ }^{60}$ Since podocyte volume density was not different between zero-hour biopsies and regular biopsies without TXG, this apparent glomerular "shrinkage" cannot simply be explained by prior "inflation" of the glomeruli with preservation solution as the authors speculated. ${ }^{60}$ Also, prevention of glomerular hypertrophy due to cyclosporin $\mathrm{A}$, as has been shown in uninephrectomized rats, ${ }^{61}$ is an unlikely explanation for the lack of initial hypertrophy, since glomerular hypertrophy occurs later during the development of TXG under the same immunosuppression. This is reflected in the volume increase between the biopsies without TxG and the nephrectomy specimens with TxG. This increase in glomerular volume can be explained by compensatory hypertrophy as laid out in the Brenner hypothesis ${ }^{62,63}$ and already discussed before as a cause of renal transplant failure. ${ }^{64,65}$ In summary, it can be concluded that podocytopenia in TxG is neither purely absolute nor purely relative; it is, rather, a mixed form, with decreased podocyte numbers in hypertrophic glomeruli. The podocyte loss that leads to the "absolute" component of podocytopenia in TxG can potentially be due to necrosis, apoptosis, and/or detachment. Glomerular necrosis is not usually seen in transplant kidneys. Therefore, podocyte loss in TxG likely occurs only by apoptosis, by detachment with subsequent loss in the urine or a combination of both mechanisms. To the best of our knowledge, apoptosis of podocytes has only been described in vitro and in animal models but never in human specimens. Therefore, it was not surprising that TUNEL stains gave negative results in all examined glomeruli. Consequently, the results from the TUNEL stains do not exclude podocyte apoptosis as a mechanism of podocyte loss in TxG, since podocyte apoptosis is probably a slowly evolving process, resembling the slowly evolving changes in the glomerular basement membrane.

Decreased Met activation in podocytes was observed in the two biopsies preceding the diagnostic biopsy. Decreased Met signaling in podocytes could contribute to both mechanisms of podocyte loss, apoptosis and detachment. The studies of Dai et al. ${ }^{46}$ in podocyte-specific Met-knockout mice have shown that HGF diminishes the rate of podocyte apoptosis after administration of adriamycin, a specific podocyte toxin. Their in vitro experiments in human podocytes have shown the activation of antiapoptotic AKT and ERK on HGF stimulation. ${ }^{46}$ Our in vitro experiments could confirm the activation of the antiapoptotic AKT and ERK by HGF. In addition to this, we could also demonstrate that increased expression of XIAP seems to be responsible for the antiapoptotic effects of HGF on podocytes. Therefore, it is conceivable that a decrease in HGF signaling from GECs to podocytes likely causes a continuously but minimally increased rate of podocyte apoptosis that is not apparent in TUNEL stains of standard renal biopsies. The second mechanism of podocyte loss, detachment and shedding in the urine, has already been described in native kidneys. ${ }^{24,66}$ Decreased Met signaling in podocytes could also be relevant for podocyte shedding because podocytes are anchored by $\alpha 3 \beta 1$ integrins to the glomerular basement membrane. ${ }^{67}$ HGF/Met signaling has been shown to increase the avidity of various integrins, including $\beta 1$ through $\beta 5 .^{68}$ Therefore, decreased Met signaling in podocytes could loosen the integrin anchoring to the glomerular basement membrane, causing podocyte detachment. Since urine samples were not available for examination in the present study, podocyte shedding needs further evaluation in prospective studies with carefully selected examination methods, since not all of them deliver valid results. ${ }^{69}$ Of course, the present retrospective study does not allow us to prove a causal relationship between the podocyte loss and the observed perturbation in the glomerular HGF/Met signaling. Nevertheless, 
based on the results above, the following pathophysiologic sequence is proposed: antiapoptotic Met activation is decreased in podocytes during the early development of TxG, but no longer at the time of diagnosis. The immunohistochemical stains suggest that, in this phase, glomerular HGF is mostly produced by GECs, and the glomerular HGF mRNA levels indicate a decreased expression during the early phase of the development of TxG. Therefore, the present results support the hypothesis that reduced HGF production by damaged GECs disrupts Met signaling in podocytes. This suggests a novel pathophysiologic pathway, how primary damage to GECs could lead to secondary podocyte damage by disruption of the cytokine cross talk. This cross talk between GECs and podocytes has recently found much interest. However, research has focused only on the signaling from podocytes to GECs, which is mainly mediated by VEGF-A and its various isoforms ${ }^{70-73}$ According to our data, a reciprocal signal mediator, from GECs to podocytes, could indeed be HGF. According to the already mentioned study in podocyte-specific Met-knockout mice, the Met signaling does not seem to be required for maturation, differentiation, or proper function of podocytes in physiological states. However, on podocyte stress, an intact HGF/Met axis seems to confer protection against apoptosis. ${ }^{46}$ Podocytes in transplants are also subject to stressors, among them cyclosporin A and profibrotic cytokines. In this situation, podocyte survival is probably dependent on intact HGF signaling from GECs. Indeed, HGF has been shown to counteract the proapoptotic effects of cyclosporin A. ${ }^{40}$ In addition, Met signaling also counteracts the effects of TGF- $\beta,{ }^{74}$ a profibrotic cytokine pivotal in fibrosis of native ${ }^{75,76}$ and transplant 77,78 kidneys, that induces apoptosis in podocytes. ${ }^{45}$ Disruption of HGF/Met signaling from GECs to podocytes could also be of importance in other glomerular diseases with secondary FSGS, in which GECs are a target, namely all forms of thrombotic microangiopathies and membranoproliferative glomerulonephritis type I. Furthermore, possible changes in the reciprocal signaling patterns from podocytes to GECs that are induced by decreased Met signaling in podocytes could be of interest. These changes could establish a vicious circle of GECs damaging podocytes damaging GECs, which will be addressed in future experiments.

Among the demographic parameters evaluated in the present study, only donor age and lowest serum creatinine level within the first 6 weeks after transplantation were higher in the $\mathrm{T} \times \mathrm{G}$ patients. These two parameters could reflect a limited regenerative potential of the kidney transplant, potentially predisposing to TxG. None of the examined histological or ultrastructural parameters, including C4d staining, were significantly different between the patient and the control cohorts (Table 2); this could be the result of the rather small sample size. Clearly, the lack of evidence for a humoral contribution to TxG development is a limitation of the present study. We were not able to provide any serological data regarding donorreactive antibodies, which are considered a key factor in the development of TxG. ${ }^{8,79,80}$ Also, no difference could be found in the prevalence of panel reactive antibodies at the time of transplantation between the patients and the controls. Still, the higher number of HLA mismatches in the TxG cohort supports the role of donor-reactive antibodies for TXG in our cohorts.

Apart from donor-reactive antibody-mediated injury, other types of injury against GECs, for example calcineurin inhibitor toxicity or hypertension, could also contribute to the lesion that is called TxG. This is best illustrated in the transplant nephrectomy specimens, which also showed severe chronic calcineurin inhibitor arteriolopathy and benign nephrosclerosis. Therefore, examination of final common pathways as reflected in the HGF/Met signaling from GECs to podocytes seem to be a more integrative approach for risk assessment of TxG development. Ancillary techniques such as the immunohistochemical examination of Met phosphorylation in podocytes or quantification of glomerular HGF mRNA via realtime PCR could turn into promising tools to identify patients at risk for earlier TXG development. This approach could provide information beyond the humoral focus of the Banff components. However, these tools need further evaluation in prospective studies before they could become part of the pathologist's routine armamentarium.

The activation of Met on mesangial cells as seen in both patient and control biopsies, which could lead to mesangioproliferation, a common but nonspecific finding in renal transplants, shows the possible adverse effects of glomerular Met activation. HGF secretion is probably rather tightly regulated in the glomerulus. This limits future therapeutic options aimed at stimulation of HGF secretion or activation of Met to prevent podocyte loss in renal transplants. Besides the potential unwanted effect of mesangioproliferation, increased Met signaling has been shown to be involved in crescent formation, ${ }^{81}$ proteinuria, ${ }^{82}$ and down-regulation of nephrin. ${ }^{83}$ Met is also known as a proto-oncogene ${ }^{84}$ linked to hereditary papillary renal cell carcinoma ${ }^{85}$ and other neoplasms. ${ }^{39}$ All therapeutic approaches aiming at a systemic activation of Met could increase the risk of neoplasia. Nevertheless, promising results have been obtained with HGF therapy in renal fibrosis models of native kidneys, ${ }^{38,86,87}$ in calcineurin inhibitor nephropathy, ${ }^{88,89}$ and transplanted kidneys. ${ }^{90,91}$ The risks, benefits, and modalities of HGF therapy in kidney transplants should be further examined.

\section{References}

1. Meier-Kriesche HU, Schold JD, Srinivas TR, Kaplan B: Lack of improvement in renal allograft survival despite a marked decrease in acute rejection rates over the most recent era. Am J Transplant 2004, 4:378-383

2. Racusen LC, Solez K, Colvin RB, Bonsib SM, Castro MC, Cavallo T, Croker BP, Demetris AJ, Drachenberg CB, Fogo AB, Furness P, Gaber LW, Gibson IW, Glotz D, Goldberg JC, Grande J, Halloran PF, Hansen HE, Hartley B, Hayry PJ, Hill CM, Hoffman EO, Hunsicker LG, Lindblad AS, Yamaguchi Y, et al.: The Banff 97 working classification of renal allograft pathology. Kidney Int 1999, 55:713-723

3. Cosio FG, Gloor JM, Sethi S, Stegall MD: Transplant glomerulopathy Am J Transplant 2008, 8:492-496

4. Colvin RB: Antibody-mediated renal allograft rejection: diagnosis and pathogenesis. J Am Soc Nephrol 2007, 18:1046-1056 
5. Nankivell BJ, Chapman JR: Chronic allograft nephropathy: current concepts and future directions. Transplantation 2006, 81:643-654

6. Solez K, Colvin RB, Racusen LC, Sis B, Halloran PF, Birk PE, Campbell PM, Cascalho M, Collins AB, Demetris AJ, Drachenberg CB, Gibson IW, Grimm PC, Haas M, Lerut E, Liapis H, Mannon RB, Marcus PB, Mengel M, Mihatsch MJ, Nankivell BJ, Nickeleit V, Papadimitriou JC, Platt JL, Randhawa P, Roberts I, Salinas-Madriga L, Salomon DR, Seron D, Sheaff M, Weening JJ: Banff '05 Meeting Report: differential diagnosis of chronic allograft injury and elimination of chronic allograft nephropathy ('CAN'). Am J Transplant 2007. 7:518-526

7. Li C, Yang CW: The pathogenesis and treatment of chronic allograft nephropathy. Nat Rev Nephrol 2009, 5:513-519

8. Gloor JM, Sethi S, Stegall MD, Park WD, Moore SB, Degoey S, Griffin MD, Larson TS, Cosio FG: Transplant glomerulopathy: subclinical incidence and association with alloantibody. Am J Transplant 2007 , 7:2124-2132

9. Wavamunno MD, O'Connell PJ, Vitalone M, Fung CL, Allen RD, Chapman JR, Nankivell BJ: Transplant glomerulopathy: ultrastructural abnormalities occur early in longitudinal analysis of protocol biopsies. Am J Transplant 2007, 7:2757-2768

10. Monga G, Mazzucco G, Novara R, Reale L: Intertubular capillary changes in kidney allografts: an ultrastructural study in patients with transplant glomerulopathy. Ultrastruct Pathol 1990, 14:201-209

11. Ivanyi B, Fahmy H, Brown H, Szenohradszky P, Halloran PF, Solez K: Peritubular capillaries in chronic renal allograft rejection: a quantitative ultrastructural study. Hum Pathol 2000, 31:1129-1138

12. Sis B, Campbell PM, Mueller T, Hunter C, Cockfield SM, Cruz J, Meng C, Wishart D, Solez K, Halloran PF: Transplant glomerulopathy, late antibody-mediated rejection and the ABCD tetrad in kidney allograft biopsies for cause. Am J Transplant 2007, 7:1743-1752

13. Regele H, Bohmig GA, Habicht A, Gollowitzer D, Schillinger M, Rockenschaub S, Watschinger B, Kerjaschki D, Exner M: Capillary deposition of complement split product C4d in renal allografts is associated with basement membrane injury in peritubular and glomerular capillaries: a contribution of humoral immunity to chronic allograft rejection. J Am Soc Nephrol 2002, 13:2371-2380

14. Einecke G, Sis B, Reeve J, Mengel M, Campbell PM, Hidalgo LG, Kaplan B, Halloran PF: Antibody-mediated microcirculation injury is the major cause of late kidney transplant failure. Am J Transplant 2009, 9:2520-2531

15. Perkowska-Ptasinska A, Ciszek M, Chmura A, Galazka Z, Paczek L, Durlik M: Transplant glomerulopathy: clinical and pathological correlations. Transplant Proc 2009, 41:141-149

16. Patrakka J, Tryggvason K: New insights into the role of podocytes in proteinuria. Nat Rev Nephrol 2009, 5:463-468

17. Fries JW, Sandstrom DJ, Meyer TW, Rennke HG: Glomerular hypertrophy and epithelial cell injury modulate progressive glomerulosclerosis in the rat. Lab Invest 1989, 60:205-218

18. Kriz W, Kretzler M, Nagata M, Provoost AP, Shirato I, Uiker S, Sakai T, Lemley KV: A frequent pathway to glomerulosclerosis: deterioration of tuft architecture-podocyte damage-segmental sclerosis. Kidney Blood Press Res 1996, 19:245-253

19. Chen CA, Hwang JC, Guh JY, Chang JM, Lai YH, Chen HC: Reduced podocyte expression of alpha3beta1 integrins and podocyte depletion in patients with primary focal segmental glomerulosclerosis and chronic PAN-treated rats. J Lab Clin Med 2006, 147:74-82

20. Lemley KV, Lafayette RA, Safai M, Derby G, Blouch K, Squarer A, Myers BD: Podocytopenia and disease severity in IgA nephropathy. Kidney Int 2002, 61:1475-1485

21. Wang G, Lai FM, Kwan BC, Lai KB, Chow KM, Li PK, Szeto CC: Podocyte loss in human hypertensive nephrosclerosis. Am J Hypertens 2009, 22:300-306

22. Pagtalunan ME, Miller PL, Jumping-Eagle S, Nelson RG, Myers BD, Rennke HG, Coplon NS, Sun L, Meyer TW: Podocyte loss and progressive glomerular injury in type II diabetes. J Clin Invest 1997, 99:342-348

23. Steffes MW, Schmidt D, McCrery R, Basgen JM: Glomerular cell number in normal subjects and in type 1 diabetic patients. Kidney Int 2001, 59:2104-2113

24. Petermann AT, Krofft R, Blonski M, Hiromura K, Vaughn M, Pichler R, Griffin S, Wada T, Pippin J, Durvasula R, Shankland SJ: Podocytes that detach in experimental membranous nephropathy are viable. Kidney Int 2003, 64:1222-1231
25. Pippin J, Kumar V, Stein A, Jablonski P, Shankland SJ, Davis CL: The contribution of podocytes to chronic allograft nephropathy. Nephron Exp Nephrol 2009, 111:e1-e10

26. Nagata M, Nakayama K, Terada Y, Hoshi S, Watanabe T: Cell cycle regulation and differentiation in the human podocyte lineage. Am $J$ Pathol 1998, 153:1511-1520

27. Adamczak M, Gross ML, Krtil J, Koch A, Tyralla K, Amann K, Ritz E: Reversal of glomerulosclerosis after high-dose enalapril treatment in subtotally nephrectomized rats. J Am Soc Nephrol 2003, 14:28332842

28. Nakamura T, Nawa K, Ichihara A: Partial purification and characterization of hepatocyte growth factor from serum of hepatectomized rats. Biochem Biophys Res Commun 1984, 122:1450-1459

29. Russell WE, McGowan JA, Bucher NL: Partial characterization of a hepatocyte growth factor from rat platelets. J Cell Physiol 1984, 119:183-192

30. Nakamura T, Nawa K, Ichihara A, Kaise N, Nishino T: Purification and subunit structure of hepatocyte growth factor from rat platelets. FEBS Lett 1987, 224:311-316

31. Miyazawa K, Tsubouchi H, Naka D, Takahashi K, Okigaki M, Arakaki N, Nakayama H, Hirono S, Sakiyama O, Takahashi K, Gohda E, Daikuhara $\mathrm{Y}$, Kitamura N: Molecular cloning and sequence analysis of cDNA for human hepatocyte growth factor. Biochem Biophys Res Commun 1989, 163:967-973

32. Nakamura T, Nishizawa T, Hagiya M, Seki T, Shimonishi M, Sugimura A, Tashiro K, Shimizu S: Molecular cloning and expression of human hepatocyte growth factor. Nature 1989, 342:440-443

33. Ishibashi K, Sasaki S, Sakamoto H, Nakamura Y, Hata T, Nakamura T, Marumo F: Hepatocyte growth factor is a paracrine factor for renal epithelial cells: stimulation of DNA synthesis and NA,K-ATPase activity. Biochem Biophys Res Commun 1992, 182:960-965

34. Matsumoto K, Nakamura T: Hepatocyte growth factor: renotropic role and potential therapeutics for renal diseases. Kidney Int 2001, 59: 2023-2038

35. Igawa T, Matsumoto K, Kanda S, Saito Y, Nakamura T: Hepatocyte growth factor may function as a renotropic factor for regeneration in rats with acute renal injury. Am J Physiol 1993, 265:F61-F69

36. Longati $\mathrm{P}$, Albero $\mathrm{D}$, Comoglio PM: Hepatocyte growth factor is a pleiotropic factor protecting epithelial cells from apoptosis. Cell Death Differ 1996, 3:23-28

37. Yamasaki N, Nagano T, Mori-Kudo I, Tsuchida A, Kawamura T, Seki $\mathrm{H}$, Taiji M, Noguchi H: Hepatocyte growth factor protects functional and histological disorders of $\mathrm{HgCl}(2)$-induced acute renal failure mice. Nephron 2002, 90:195-205

38. Yang J, Liu Y: Blockage of tubular epithelial to myofibroblast transition by hepatocyte growth factor prevents renal interstitial fibrosis. J Am Soc Nephrol 2002, 13:96-107

39. Ma PC, Maulik G, Christensen J, Salgia R: c-Met: structure, functions and potential for therapeutic inhibition. Cancer Metastasis Rev 2003 , 22:309-325

40. Fornoni A, Li H, Foschi A, Striker GE, Striker LJ: Hepatocyte growth factor, but not insulin-like growth factor I, protects podocytes against cyclosporin A-induced apoptosis. Am J Pathol 2001, 158:275-280

41. Liu Y: Hepatocyte growth factor in kidney fibrosis: therapeutic potential and mechanisms of action. Am J Physiol Renal Physiol 2004, 287:F7-F16

42. Khwaja A, Lehmann K, Marte BM, Downward J: phosphoinositide 3-kinase induces scattering and tubulogenesis in epithelial cells through a novel pathway. J Biol Chem 1998, 273:18793-18801

43. Besser D, Bardelli A, Didichenko S, Thelen M, Comoglio PM, Ponzetto $C$, Nagamine Y: Regulation of the urokinase-type plasminogen activator gene by the oncogene Tpr-Met involves GRB2. Oncogene 1997, 14:705-711

44. Manning BD, Cantley LC: AKT/PKB signaling: navigating downstream. Cell 2007, 129:1261-1274

45. Schiffer M, Bitzer M, Roberts IS, Kopp JB, ten Dijke P, Mundel P, Bottinger EP: Apoptosis in podocytes induced by TGF-beta and Smad7. J Clin Invest 2001, 108:807-816

46. Dai C, Saleem MA, Holzman LB, Mathieson P, Liu Y: Hepatocyte growth factor signaling ameliorates podocyte injury and proteinuria. Kidney Int 2010, 77:962-973

47. Sanden SK, Wiggins JE, Goyal M, Riggs LK, Wiggins RC: Evaluation of a thick and thin section method for estimation of podocyte number, glomerular volume, and glomerular volume per podocyte in rat kidney 
with Wilms' tumor-1 protein used as a podocyte nuclear marker. J Am Soc Nephrol 2003, 14:2484-2493

48. Racusen LC, Colvin RB, Solez K, Mihatsch MJ, Halloran PF, Campbel PM, Cecka MJ, Cosyns JP, Demetris AJ, Fishbein MC, Fogo A, Furness P, Gibson IW, Glotz D, Hayry P, Hunsickern L, Kashgarian M, Kerman R, Magil AJ, Montgomery R, Morozumi K, Nickeleit V, Randhawa P, Regele H, Seron D, Seshan S, Sund S, Trpkov K: Antibodymediated rejection criteria: an addition to the Banff 97 classification of renal allograft rejection. Am J Transplant 2003, 3:708-714

49. Racusen LC, Halloran PF, Solez K: Banff 2003 meeting report: new diagnostic insights and standards. Am J Transplant 2004, 4:15621566

50. Solez K, Colvin RB, Racusen LC, Haas M, Sis B, Mengel M, Halloran PF, Baldwin W, Banfi G, Collins AB, Cosio F, David DS, Drachenberg C, Einecke G, Fogo AB, Gibson IW, Glotz D, Iskandar SS, Kraus E, Lerut E, Mannon RB, Mihatsch M, Nankivell BJ, Nickeleit V, Papadimitriou JC, Randhawa P, Regele H, Renaudin K, Roberts I, Seron D, Smith RN, Valente M: Banff 07 classification of renal allograft pathology: updates and future directions. Am J Transplant 2008, 8:753-760

51. Cen L, Arnoczky KJ, Hsieh FC, Lin HJ, Qualman SJ, Yu S, Xiang H, Lin $\mathrm{J}$ : Phosphorylation profiles of protein kinases in alveolar and embryonal rhabdomyosarcoma. Mod Pathol 2007, 20:936-946

52. Benvenuti S, Comoglio PM: The MET receptor tyrosine kinase in invasion and metastasis. J Cell Physiol 2007, 213:316-325

53. Eder JP, Vande Woude GF, Boerner SA, LoRusso PM: Novel therapeutic inhibitors of the c-Met signaling pathway in cancer. Clin Cancer Res 2009, 15:2207-2214

54. Mundel P, Kriz W: Cell culture of podocytes. Exp Nephrol 1996 4:263-266

55. Deveraux QL, Takahashi R, Salvesen GS, Reed JC: X-linked IAP is a direct inhibitor of cell-death proteases. Nature 1997, 388:300-304

56. Deveraux QL, Roy N, Stennicke HR, Van Arsdale T, Zhou Q, Srinivasula SM, Alnemri ES, Salvesen GS, Reed JC: IAPs block apoptotic events induced by caspase- 8 and cytochrome $\mathrm{c}$ by direct inhibition of distinct caspases. EMBO J 1998, 17:2215-2223

57. World Medical Association: WMA Declaration of Helsinki: Ethical Principles for Medical Research Involving Human Subjects. Ferney-Voltaire, France: World Medical Association, 2008. Available at http:// www.wma.net/en/30publications/10policies/b3/

58. Kriz W, LeHir M: Pathways to nephron loss starting from glomerular diseases: insights from animal models. Kidney Int 2005, 67:404-419

59. Kriz W: The pathogenesis of 'classic' focal segmental glomerulosclerosis: lessons from rat models. Nephrol Dial Transplant 2003, 18(Suppl 6):vi39-vi44

60. Osterby R, Nyberg G, Karlberg I, Svalander C: Glomerular volume in kidneys transplanted into diabetic and non-diabetic patients. Diabet Med 1992, 9:144-149

61. Schurek HJ, Neumann KH, Jesinghaus WP, Aeikens B, Wonigeit K: Influence of cyclosporine A on adaptive hypertrophy after unilatera nephrectomy in the rat. Clin Nephrol 1986, 25(Suppl 1):S144-S147

62. Brenner BM, Meyer TW, Hostetter TH: Dietary protein intake and the progressive nature of kidney disease: the role of hemodynamically mediated glomerular injury in the pathogenesis of progressive glomerular sclerosis in aging, renal ablation, and intrinsic renal disease. N Engl J Med 1982, 307:652-659

63. Brenner BM: Nephron adaptation to renal injury or ablation. Am $J$ Physiol 1985, 249:F324-F337

64. Terasaki PI, Koyama H, Cecka JM, Gjertson DW: The hyperfiltration hypothesis in human renal transplantation. Transplantation 1994, 57: 1450-1454

65. Sola R, Paredes D, Antonijoan RM, Estorch M, Vila LP, Guirado LL, Diaz JM, Gich I, Barbanoj MJ: Glomerular hyperfiltration, intrarenal hemodynamics, and chronic allograft nephropathy: physiopathology of chronic allograft nephropathy. Transplant Proc 2002, 34:340-342

66. Garovic VD, Wagner SJ, Turner ST, Rosenthal DW, Watson WJ, Brost BC, Rose CH, Gavrilova L, Craigo P, Bailey KR, Achenbach J, Schiffer M, Grande JP: Urinary podocyte excretion as a marker for preeclampsia. Am J Obstet Gynecol 2007, 196:320 e321-e327

67. Kretzler M: Regulation of adhesive interaction between podocytes and glomerular basement membrane. Microsc Res Tech 2002, 57 : 247-253
68. Trusolino L, Cavassa S, Angelini P, Ando M, Bertotti A, Comoglio PM, Boccaccio C: HGF/scatter factor selectively promotes cell invasion by increasing integrin avidity. FASEB J 2000, 14:1629-1640

69. Skoberne A, Konieczny A, Schiffer M: Glomerular epithelial cells in the urine: what has to be done to make them worthwhile?. Am J Physiol Renal Physiol 2009, 296:F230-F241

70. Eremina V, Baelde HJ, Quaggin SE: Role of the VEGF-a signaling pathway in the glomerulus: evidence for crosstalk between components of the glomerular filtration barrier. Nephron Physiol 2007, 106:32-37

71. Eremina V, Cui S, Gerber H, Ferrara N, Haigh J, Nagy A, Ema M, Rossant J, Jothy S, Miner JH, Quaggin SE: Vascular endothelial growth factor A signaling in the podocyte-endothelial compartment is required for mesangial cell migration and survival. J Am Soc Nephrol 2006, 17:724-735

72. Eremina V, Quaggin SE: The role of VEGF-A in glomerular development and function. Curr Opin Nephrol Hypertens 2004, 13:9-15

73. Schumacher VA, Jeruschke S, Eitner F, Becker JU, Pitschke G, Ince Y, Miner JH, Leuschner I, Engers R, Everding AS, Bulla M, RoyerPokora B: Impaired glomerular maturation and lack of VEGF165b in Denys-Drash syndrome. J Am Soc Nephrol 2007, 18:719-729

74. Florquin S, Rouschop KM: Reciprocal functions of hepatocyte growth factor and transforming growth factor-beta1 in the progression of renal diseases: a role for CD44? Kidney Int Suppl 2003, S15-S20

75. Border WA, Noble NA, Yamamoto T, Harper JR, Yamaguchi Y, Pierschbacher MD, Ruoslahti E: Natural inhibitor of transforming growth factor-beta protects against scarring in experimental kidney disease. Nature 1992, 360:361-364

76. Sato M, Markiewicz M, Yamanaka M, Bielawska A, Mao C, Obeid LM, Hannun YA, Trojanowska M: Modulation of transforming growth factor-beta (TGF-beta) signaling by endogenous sphingolipid mediators. J Biol Chem 2003, 278:9276-9282

77. Gaciong Z, Koziak K, Religa P, Lisiecka A, Morzycka-Michalik M, Rell K, Kozlowska-Boszko B, Lao M: Increased expression of growth factors during chronic rejection of human kidney allograft. Transplant Proc 1995, 27:928-929

78. Shihab FS, Yamamoto T, Nast CC, Cohen AH, Noble NA, Gold LI, Border WA: Transforming growth factor-beta and matrix protein expression in acute and chronic rejection of human renal allografts. J Am Soc Nephrol 1995, 6:286-294

79. Mauiyyedi S, Crespo M, Collins AB, Schneeberger EE, Pascual MA Saidman SL, Tolkoff-Rubin NE, Williams WW, Delmonico FL, Cosimi $A B$, Colvin RB: Acute humoral rejection in kidney transplantation: II. Morphology, immunopathology, and pathologic classification. J Am Soc Nephrol 2002, 13:779-787

80. Palomar R, Lopez-Hoyos M, Pastor JM, Fernandez-Fresnedo G, Rodrigo E, Ruiz JC, Cotorruelo JG, Valero R, Castaneda O, San Segundo D, Arias M: Impact of HLA antibodies on transplant glomerulopathy. Transplant Proc 2005, 37:3830-3832

81. Rampino T, Gregorini M, Camussi G, Conaldi PG, Soccio G, Maggio M, Bottelli A, Dal Canton A: Hepatocyte growth factor and its receptor Met are induced in crescentic glomerulonephritis. Nephrol Dial Transplant 2005, 20:1066-1074

82. Kusumoto K, Ido A, Moriuchi A, Katsura T, Kim I, Takahama Y, Numata M, Kodama M, Hasuike S, Nagata K, Uto H, Inui K, Tsubouchi $\mathrm{H}$ : Repeated intravenous injection of recombinant human hepatocyte growth factor ameliorates liver cirrhosis but causes albuminuria in rats. Int J Mol Med 2006, 17:503-509

83. Takano Y, Yamauchi K, Hiramatsu N, Kasai A, Hayakawa K, Yokouchi M, Yao J, Kitamura M: Recovery and maintenance of nephrin expression in cultured podocytes and identification of HGF as a repressor of nephrin. Am J Physiol Renal Physiol 2007, 292:F1573-F1582

84. Goldstein D, Leavitt J: Expression of neoplasia-related proteins of chemically transformed HUT fibroblasts in human osteosarcoma HOS fibroblasts and modulation of actin expression upon elevation of tumorigenic potential. Cancer Res 1985, 45:3256-3261

85. Schmidt L, Duh FM, Chen F, Kishida T, Glenn G, Choyke P, Scherer SW, Zhuang Z, Lubensky I, Dean M, Allikmets R, Chidambaram A, Bergerheim UR, Feltis JT, Casadevall C, Zamarron A, Bernues M, Richard S, Lips CJ, Walther MM, Tsui LC, Geil L, Orcutt ML, Stackhouse T, Lipan J, Slife L, Brauch H, Decker J, Niehans G, Hughson MD, Moch H, Storkel S, Lerman MI, Linehan WM, Zbar B: Germline and somatic mutations in the tyrosine kinase domain of the MET proto-oncogene in papillary renal carcinomas. Nat Genet 1997, 16 : $68-73$ 
86. Mizuno S, Kurosawa T, Matsumoto K, Mizuno-Horikawa Y, Okamoto M, Nakamura T: Hepatocyte growth factor prevents renal fibrosis and dysfunction in a mouse model of chronic renal disease. J Clin Invest 1998, 101:1827-1834

87. Dworkin LD, Gong R, Tolbert E, Centracchio J, Yano N, Zanabli AR, Esparza A, Rifai A: Hepatocyte growth factor ameliorates progression of interstitial fibrosis in rats with established renal injury. Kidney Int 2004, 65:409-419

88. Yazawa K, Isaka Y, Takahara S, Imai E, Ichimaru N, Shi Y, Namba Y, Okuyama A: Direct transfer of hepatocyte growth factor gene into kidney suppresses cyclosporin A nephrotoxicity in rats. Nephrol Dial Transplant 2004, 19:812-816
89. Mizui M, Isaka Y, Takabatake Y, Mizuno S, Nakamura T, Ito T, Imai E, Hori M: Electroporation-mediated HGF gene transfer ameliorated cyclosporine nephrotoxicity. Kidney Int 2004, 65:2041-2053

90. Azuma H, Takahara S, Matsumoto K, Ichimaru N, Wang JD, Moriyama T, Waaga AM, Kitamura M, Otsuki Y, Okuyama A, Katsuoka Y, Chandraker A, Sayegh $\mathrm{MH}$, Nakamura T: Hepatocyte growth factor prevents the development of chronic allograft nephropathy in rats. J Am Soc Nephrol 2001, 12:1280-1292

91. Herrero-Fresneda I, Torras J, Franquesa M, Vidal A, Cruzado JM Lloberas N, Fillat C, Grinyo JM: HGF gene therapy attenuates rena allograft scarring by preventing the profibrotic inflammatory-induced mechanisms. Kidney Int 2006, 70:265-274 